\title{
Donepezil and $\alpha$-synuclein Constipation: A 48 Month Follow-Up
}

\author{
Charles M. Lepkowsky 1* \\ ${ }^{1}$ Independent Practice, 1143 Deer Trail Lane, Solvang, California 93463, United States \\ Received Date: February 3, 2021 Accepted Date: March 03, 2021 Published Date: April 02, 2021 \\ Citation: Charles M. Lepkowsky (2021). Donepezil and $\alpha$-synuclein Constipation: A 48 Month Follow-Up. \\ POJ Clin Case Rep. 3(1):1-7. DOI: https://doi.org/10.32648/2639-3298/3/1/001 \\ *Corresponding Author: Charles M. Lepkowsky, PhD, Independent Practice, 1143 Deer Trail Lane, Solvang, \\ California 93463, United States, E-mail: clepkowsky@gmail.com.
}

\begin{abstract}
In a case study, four patients diagnosed at different stages of disease progression with the $\alpha$-synuclein or Lewy body disorders Parkinson's disease (PD) and Neurocognitive Disorder with Lewy Bodies (NCDLB) were treated with the acetylcholinesterase inhibitor (AChEI) Donepezil to address the symptoms of constipation, obstipation and impaction. The use of Donepezil was associated with significant symptom reduction for each of the four patients. In follow-up studies conducted at intervals of six, twelve, eighteen, thirty-six and forty-eight months, symptom improvement was maintained with no apparent reduction in bowel motility, nor the emergence of any new symptoms. The results suggest that the AChEI Donepezil can have long-term benefit in reducing the symptoms of constipation, obstipation and impaction in patients with $\alpha$-synuclein disorders.
\end{abstract}

Keywords: Neurocognitive Disorder with Lewy Bodies, Parkinson's disease, constipation, Donepezil, acetylcholinesterase inhibitor

\section{INTRODUCTION}

In a case study, four patients diagnosed at different stages of disease progression with $\alpha$-synuclein protein pathology, or Lewy body disorders including Parkinson's disease (PD) and Neurocognitive Disorder with Lewy Bodies (NCDLB) were treated with the acetylcholinesterase inhibitor (AChEI) Donepezil to address the symptoms of constipation, obstipation, and impaction [1]. In the context of the case study, constipation refers to reduced frequency of bowel movements to less than once in two days, obstipation is defined as severe constipation, with frequency of bowel movements reduced to less than once a week, and impaction is defined as complete cessation of bowel function, also referred to as blockage of the lower intestine. The study was based on research demonstrating that bowel immotility, presenting symptomatically as constipation, obstipation and impaction is a consequence of $\alpha$-synuclein impairment of the predominantly cholinergic neurotransmitter pathways in the myenteric plexus (MP) and the colonic submucosal plexus (CSMP) [2-10].

Complicating the treatment picture, PD and NCDLB patients with significant Parkinsonian features are often prescribed L-dopa agents including Carbidopa-Levodopa (brand names include Sinemet and Stalevo) to preserve basic motor functions including gait and balance $[11,12]$. The potential side effects of L-dopa agents include bowel immotility [13]. Constipation, obstipation and impaction significantly diminish the patient's quality of life, and create daily hardship for providers of care $[14,15]$. Conventional forms of treatment including over- the-counter medications have proven largely ineffective for reducing symptoms of constipation, obstipation and impaction in patients with $\alpha$-synuclein pathology [16].

\section{Donepezil and Constipation: Cholinergic Agonist Use in NCDLB and PD}

To counter cholinergic impairment caused by $\alpha$-synucleinopathy, including PD motor symptoms, gait dysfunction, levodopa-induced dyskinesias, cognitive deterioration, psychosis, sleep abnormalities, autonomic dysfunction, and altered olfactory function, PD and NCDLB patients have long been prescribed acetylcholinesterase inhibitors (AChEIs) [17-22]. The pathophysiology of these symptoms begins with alteration of the cholinergic tone in the striatum and/or to degeneration of cholinergic nuclei, most importantly the nucleus basalis magnocellularis and the pedunculopontine nucleus [21]. Among the AChEl's, Donepezil has demonstrated efficacy for mitigating cholinergic impairment in PD and NCDLB patients, without exacerbating Parkinsonian symptoms or generating new symptoms [23-28]. In a nongeriatric affective patient population, Donepezil was also shown to be effective in reducing constipation [29]. In a population diagnosed with severe bowel immotility, Donepezil increased bowel contractions 477\% [30]. Donepezil is a specific, reversible acetylcholinesterase inhibitor [31, 32]. Donepezil increases acetylcholine levels by limiting the action of the acetylcholine-hydrolyzing enzyme acetylcholinesterase, effectively mitigating the symptoms of cholinergic impairment [33]. Because it also independently

Copyright: (2021 Charles M. Lepkowsky. This is an open-access article distributed under the terms of the Creative Commons Attribution License, which permits unrestricted use, distribution, and reproduction in any medium, provided the original author and source are credited. 
facilitates neuronal nicotinic acetylcholine receptors [34], Donepezil plays a dual role in reducing cholinergic impairment. Donepezil's "dual action" has long made it a drug of choice for addressing symptoms of cholinergic impairment [22, 23, 25, 31, 34].

\section{Hypothesis}

Well documented as an effective agent for reducing cholinergic impairment [23-28], Donepezil has also been shown to reduce symptoms of constipation in nongeriatric affective patients [29] and increase bowel contractions in patients with severe bowel immotility [30]. It was hypothesized thatDonepezil would reduce the enteric nervous system (ENS) symptoms of constipation, obstipation and impaction consequent to $\alpha$ synucleinopathy-based cholinergic impairment in the MP and CSMP in patients diagnosed with PD and NCDLB. A secondary hypothesis was that Donepezil would reduce bowel immotility in patients using Carbidopa-Levodopa, often prescribed to Lewy body patients with Parkinsonian features.

\section{Methods}

In order to assess Donepezil's efficacy for mitigating $\alpha$ synucleinopathy-based bowel immotility, a case study was conducted. Donepezil in daily doses varying from 5 to 10 $\mathrm{mg}$ was orally administered to four patients diagnosed with PD and NCDLB at varying levels of disease progression with symptoms of constipation, obstipation and/or impaction. Based on a series of MRI's, neurological assessments, CT scans and Modified Hoehn and Yahr scores[35], two of the patients (Patient $A$ and Patient $B$ ) had been diagnosed with PD. Patient A was a male aged 51 years at the time of diagnosis and 53 years at the time Donepezil was initially administered. Patient $B$ was a male aged 70 years at the time of diagnosis and at the time that Donepezil was initially administered. Based on a series of MRI's, CT scans, neurological evaluations, and scores on the Mini-Mental State Examination (MMSE) [36], the Quick Dementia Rating System (QDRS) [37] and the Lewy Body Composite Risk Score [38], the other two patients had been diagnosed with NCDLB (Patient $C$ and Patient D). Patient $C$ was a female aged 69 years at the time of diagnosis and at the time that Donepezil was administered, and Patient $D$ was a male aged 74 years at the time of diagnosis, and 78 years at the time that Donepezil was initially administered. During the subsequent six months, one of the PD patients (Patient B) was also diagnosed with NCDLB, subsuming the PD symptoms leading to the initial PD diagnosis. Each patient was assessed before treatment, and after initiation of treatment at intervals of two, four, and six weeks, and six, twelve, eighteen, thirty-six and forty-eight months.

\section{Results}

Two weeks after the introduction of orally administered Donepezil at daily doses of $5 \mathrm{mg}$, assessment indicated significant reduction of the symptoms of constipation, obstipation and impaction. In the current context, constipation is defined as bowel movements (BMs) 3 times a week; obstipation by BMs 1-2 times a week; and impaction by BMs on a less than weekly basis, e.g., once in 2 weeks. At assessment intervals of four weeks and six weeks, symptom reduction was increased, without exacerbation of existing symptoms, nor the emergence of new symptoms at any assessment interval [1].The increase in the frequency of bowel movements (BMs) is shown in Table 1. After six months, each of the four patients was assessed in a follow-up study. Patients $A$ and $C$ demonstrated no change in symptoms. Patient B's verbal report and test scores indicated cognitive decline, so the diagnosis of NCDLB was assigned. There was evidence of disease progression in $\alpha$-synucleinopathybased cognitive and movement pathology for Patient $B$ and Patient $D$, both diagnosed with NCDLB, but no increase in the symptoms of constipation, obstipation or impaction, nor was there emergence of any new symptoms [39]. Following assessment at six months, Patient B's daily dosage of Donepezil was increased from 5 to $10 \mathrm{mg}$ to address the increases in cognitive interference (short-term memory loss and difficulty with word-finding) that led to the change in diagnosis from PD to NCDLB.

A second follow-up study was conducted twelve months after the introduction of Donepezil, using the same assessment procedure with each of the four patients. At the twelvemonth interval, none of the four patients showed any increase in symptoms of constipation, obstipation or impaction, apparent progression of any other $\alpha$-synuclein symptoms, nor the emergence of new symptoms [40]. Patient B, the NCDLB patient whose dosage of Donepezil had been doubled at six months, demonstrated some recovery of cognitive function (reductions in short-term memory loss and difficulty with word-finding). Using the same methodology, assessment at eighteen months indicated no changes in symptom status for any of the four patients [41].

About twenty-four months after initiation of treatment with Donepezil, Patient B (diagnosed with NCDLB) was prescribed a daily oral dose of $10 \mathrm{mg}$ of Vortioxetine. The patient had been using Levodopa-Carbidopa (Sinemet) to treat Parkinsonian features, for which Donepezil had appeared effective in countering bowel slowing, and Bupropion for depression and anxiety. Vortioxetine was added to the patient's prescriptions because it has demonstrated efficacy for reducing the symptoms of depression [42-55], anxiety [42, 56-57], and cognitive impairment[58-63]. The introduction of Vortioxetine quickly produced some unanticipated symptom consequences. Within two weeks of initiating treatment with Vortioxetine, the patient went 10 days without a bowel movement, and received emergency treatment for impaction. The patient also demonstrated increased cognitive impairment. The use of Vortioxetine was discontinued, and within two days Patient B's cognition and bowel function returned to their preVortioxetine status [64].

Using the same methodology employed at previous intervals, the four patients were again assessed thirty-six months after the initial introduction of Donepezil. Assessment indicated no increase in constipation, obstipation, or impaction in any of the four patients. Patients $A$ and $C$ showed no progression of cognitive interference, movement disorders or other a-synucleinopathy. Patients $B$ and $D$ both demonstrated progression of PD movement symptoms. None of the four patients showed indication of the emergence of new symptoms. A summary of findings is presented in Table 1. 
Table 1: Changes in Symptoms, Test Scores and Diagnosis over Time

\begin{tabular}{|c|c|c|c|c|}
\hline & $\begin{array}{l}\text { Patient A } \\
\text { Male } \\
\text { Age at Dx PD } 51 \\
\text { At start of study: } \\
\text { Age } 53 \\
\text { MODIFIED HOEHN } \\
\text { AND YAHR (H \& Y) } \\
\text { STAGE } 2.5 \\
\text { MMSE } 30 \\
\text { BM 1-2X/week } \\
\text { Initial dosage } \\
\text { Donepezil } 5 \text { mg }\end{array}$ & $\begin{array}{l}\text { Patient B } \\
\text { Male } \\
\text { Age at Dx PD } 70 \\
\text { At start of study: } \\
\text { Age 70; Dx } \\
\text { MODIFIED HOEHN } \\
\text { AND YAHR (H \& Y) } \\
\text { STAGE } 3 \\
\text { MMSE } 23 \\
\text { BM 1X/2 weeks } \\
\text { Initial dosage } \\
\text { Donepezil } 5 \text { mg }\end{array}$ & $\begin{array}{l}\text { Patient C } \\
\text { Female } \\
\text { Age at Dx NCDLB } 69 \\
\text { At start of study: } \\
\text { Age } 69 \\
\text { MODIFIED HOEHN } \\
\text { AND YAHR (H \& Y) } \\
\text { STAGE } 2 \\
\text { MMSE } 25 \\
\text { BM } 3 X / \text { week } \\
\text { Initial dosage } \\
\text { Donepezil } 5 \text { mg }\end{array}$ & $\begin{array}{l}\text { Patient D } \\
\text { Male } \\
\text { Age at Dx NCDLB } 74 \\
\text { At start of study: } \\
\text { Age } 78 \\
\text { MODIFIED HOEHN } \\
\text { AND YAHR (H \& Y) } \\
\text { STAGE } 3.5 \\
\text { MMSE } 22 \\
\text { BM 1X/2 weeks } \\
\text { Initial dosage } \\
\text { Donepezil } 5 \text { mg }\end{array}$ \\
\hline $\begin{array}{l}2 \text { week assessment } \\
2 \text { weeks: } \\
4 \text { weeks: } \\
6 \text { weeks: }\end{array}$ & $\begin{array}{l}\text { H \& Y stage } 2.5 \\
\text { MMSE } 30 \\
\text { Donepezil } 5 \text { mg } \\
\text { BM 3-4X/wk } \\
\text { BM 4-6X/week } \\
\text { BM 6-7X/week }\end{array}$ & $\begin{array}{l}\text { H \& Y stage } 3 \\
\text { MMSE } 23 \\
\text { Donepezil } 5 \text { mg } \\
\text { BM 1-2X/week } \\
\text { BM 3-4X/week } \\
\text { BM 4-5X/week }\end{array}$ & $\begin{array}{l}\text { H \& Y stage } 2 \\
\text { MMSE } 25 \\
\text { Donepezil } 5 \text { mg } \\
\text { BM 4-5X/week } \\
\text { BM 5-6X/week } \\
\text { BM 6-7X/week }\end{array}$ & $\begin{array}{l}\text { H \& Y stage } 3.5 \\
\text { MMSE } 22 \\
\text { Donepezil } 5 \text { mg } \\
\text { BM 1-2X/week } \\
\text { BM 3-4X/week } \\
\text { BM 4-5X/week }\end{array}$ \\
\hline 6 month assessment & $\begin{array}{l}\text { H \& Y stage } 2.5 \\
\text { MMSE } 30 \\
\text { Donepezil } 5 \text { mg } \\
\text { BM 6-7X/week }\end{array}$ & $\begin{array}{l}\text { H \& Y stage } 3.5 \\
\text { MMSE } 20 \\
\text { Donepezil } 5 \text { mg } \\
\text { BM 4-5X/week } \\
\text { Dx now NCDLB }\end{array}$ & $\begin{array}{l}\text { H \& Y stage } 2 \\
\text { MMSE } 25 \\
\text { Donepezil } 5 \text { mg } \\
\text { BM 6-7X/week }\end{array}$ & $\begin{array}{l}\text { H \& Y stage } 4 \\
\text { MMSE } 19 \\
\text { Donepezil } 5 \text { mg } \\
\text { BM 4-5X/week }\end{array}$ \\
\hline 12 month assessment & $\begin{array}{l}\text { H \& Y stage } 2.5 \\
\text { MMSE } 30 \\
\text { Donepezil } 5 \text { mg } \\
\text { BM 6-7X/week }\end{array}$ & $\begin{array}{l}\text { H \& Y stage } 3.5 \\
\text { MMSE } 24 \\
\text { Donepezil } 10 \text { mg } \\
\text { BM 4-5X/week }\end{array}$ & $\begin{array}{l}\text { H \& Y stage } 2.5 \\
\text { MMSE } 25 \\
\text { Donepezil } 5 \text { mg } \\
\text { BM 6-7X/week }\end{array}$ & $\begin{array}{l}\text { H \& Y stage } 2.5 \\
\text { MMSE } 19 \\
\text { Donepezil } 5 \text { mg } \\
\text { BM 4-5X/week }\end{array}$ \\
\hline 18 month assessment & $\begin{array}{l}\text { H \& Y stage } 2.5 \\
\text { MMSE } 30 \\
\text { Donepezil } 5 \text { mg } \\
\text { BM 6-7X/week }\end{array}$ & $\begin{array}{l}\text { H \& Y stage } 2.5 \\
\text { MMSE } 24 \\
\text { Donepezil } 5 \text { mg } \\
\text { BM 4-5X/week }\end{array}$ & $\begin{array}{l}\text { H \& Y stage } 2.5 \\
\text { MMSE } 25 \\
\text { Donepezil } 5 \text { mg } \\
\text { BM 6-7X/week }\end{array}$ & $\begin{array}{l}\text { H \& Y stage } 2.5 \\
\text { MMSE } 19 \\
\text { Donepezil } 5 \text { mg } \\
\text { BM 4-5X/week }\end{array}$ \\
\hline 36 month assessment & $\begin{array}{l}\text { H \& Y stage } 2.5 \\
\text { MMSE } 30 \\
\text { Donepezil } 5 \text { mg } \\
\text { BM 6-7X/week }\end{array}$ & $\begin{array}{l}\text { H \& Y stage } 2.5 \\
\text { MMSE } 24 \\
\text { Donepezil } 10 \text { mg } \\
\text { BM 4-5X/week }\end{array}$ & $\begin{array}{l}\text { H \& Y stage } 2.5 \\
\text { MMSE } 25 \\
\text { Donepezil } 5 \text { mg } \\
\text { BM 6-7X/week }\end{array}$ & $\begin{array}{l}\text { H \& Y stage } 2.5 \\
\text { MMSE } 19 \\
\text { Donepezil } 5 \text { mg } \\
\text { BM 4-5X/week }\end{array}$ \\
\hline 48 month assessment & $\begin{array}{l}\text { H \& Y stage } 2.5 \\
\text { MMSE } 30 \\
\text { Donepezil } 5 \text { mg } \\
\text { BM 6-7X/week }\end{array}$ & $\begin{array}{l}\text { H \& Y stage } 2.5 \\
\text { MMSE } 24 \\
\text { Donepezil } 10 \text { mg } \\
\text { BM 4-5X/week }\end{array}$ & $\begin{array}{l}\text { H \& Y stage } 2.5 \\
\text { MMSE } 25 \\
\text { Donepezil } 5 \text { mg } \\
\text { BM 6-7X/week }\end{array}$ & $\begin{array}{l}\text { H \& Y stage } 2.5 \\
\text { MMSE } 19 \\
\text { Donepezil } 5 \text { mg } \\
\text { BM 4-5X/week }\end{array}$ \\
\hline
\end{tabular}

\section{Discussion and Conclusions}

In four patients at varying levels of disease progression with PD and NCDLB, daily oral administration of Donepezil in doses varying from 5 to $10 \mathrm{mg}$ was associated with significant reduction in the symptoms of constipation, obstipation and/or impaction. After initiating use of Donepezil, the four patients demonstrated no symptom progression for cognitive interference, movement disorders or other $\alpha$-synucleinopathy, nor the emergence of new symptoms. Reduction in the symptoms of constipation, obstipation and/or impaction was consistent over time, assessed at intervals of two, four and six weeks, and later, at intervals of six, twelve, eighteen, thirtysix[1, 39-41, 65] and forty-eight months.

The findings from this series of case studies support the hypothesis that Donepezil can reduce $\alpha$-synucleinopathybased cholinergic impairment in the in the ENS, specifically 
the MP and CSMP, as evidenced by reductions in the symptoms of constipation, obstipation and/or impaction. The case study findings also support the hypothesis that Donepezil can counter bowel immotility consequent to the use of CarbidopaLevodopa.

The findings from this series of case studies also provide a demonstration of Vortioxetine's potential for serotonergic and cholinergic inhibition, and importantly, its reversibility [63]. Vortioxetine is metabolized by cytochrome P450 enzymes (e.g., CYP450 2D6) and subsequently by uridine diphosphate glucuronosyltransferase [66]. Initially believed to have relatively low risk for pharmacodynamic drug interactions $[67,68]$, Vortioxetine peak plasma concentration and systemic exposure are significantly increased when Vortioxetine is co-administered with the potent CYP450 2D6 inhibitor Bupropion [66]. When co-administered, Levodopa-Carbidopa (Sinemet) also significantly increases Vortioxetine peak plasma concentration and systemic exposure [69, 70]. The NCDLB patient in the case study prescribed Vortioxetine was using Bupropionand Levodopa-Carbidopa (Sinemet).

Apparently utilizing the same 5 -HT3 receptor binding site as serotonin selective reuptake inhibitors (SSRIs), the molecular mechanisms underlying Vortioxetine's site binding appear to vary from currently known 5-HT3Aorthosteric ligands. In addition to binding in a similar manner to the setron class of competitive antagonists and 5-HT by interacting with residues of the aromatic box motif in the orthosteric binding site, Vortioxetine also interacts with residues not previously described to be important for the binding of either setrons or 5-HT, including Thr176 on loop B and Val202 on loop F [71]. Following partial agonist activity, Vortioxetine mounts what has been described as a persistent and insurmountable inhibition [71]. Vortioxetine'speak plasma concentration and systemic exposure can be more than doubled by its combined interactions with Bupropion and Levodopa-Carbidopa [66, 69, 70], so its serotonergic inhibitory potential is also significantly increased.

As illustrated by the case study, the combined interaction of Bupropion and Levodopa-Carbidopa with Vortioxetine can be dramatic, in this instance apparently exacerbating Lewy Body $\alpha$-synuclein cholinergic suppression in the ENS, while the combination of Vortioxetine's serotonergic and cholinergic inhibition also significantly interfered with cognition. Although painful for the patient, this serendipitous finding contributed to the growing body of information about potential drug interactions for the relatively new drug Vortioxetine [64].

The primary focus of the case studies, however, continues to be Donepezil. Its "dual action" specifically and reversibly limits the action of the acetylcholine-hydrolyzing enzyme acetylcholinesterase [31, 32], while independently facilitating neuronal nicotinic acetylcholine receptors [34]. In combination, these two mechanisms effectively increase acetylcholine levels, with significant mitigation of symptoms attributable to cholinergic impairment [33].

The consistency of the current case study's findings over a four-year period in four patients diagnosed with degenerative $\alpha$-synuclein neurocognitive and movement disorders is encouraging. It corroborates previous research indicating that Donepezil slows or reverses cognitive symptom progression in $\alpha$-synucleinopathy, including short-term memory loss, difficulty with word-finding, hallucinations and cognitive interference [17, 18, 19, 20, 21]. It also provides a viable treatment protocol for mitigating $\alpha$-synucleinopathy-based ENS suppression of the cholinergic pathways in the MP and the CSMP, providing relief from the symptoms of constipation, obstipation, and impaction that can so dramatically reduce the Lewy Body patient's quality of life.

Further research is recommended following patients over an extended time frame to establish longitudinal outcomes, and using larger numbers of subjects matched for diagnosis, age, gender and other variables.

Conflicts of Interest and Source of Funding: The author declares no conflicts of interest in the manuscript, including financial, consultant, institutional, and other relationships that might lead to bias or a conflict of interest. The author also declares no sources of funding for the manuscript. The Santa Barbara Cottage Hospital Institutional Review Board granted a waiver (\#18-81ix) for this case study.

\section{References}

1. Lepkowsky CM. Donepezil for constipation in Lewy Body Diseases: Four case studies. Act Nerv Super. 2017;59(1):1927. doi: 10.1007/s41470-017-0004-1

2. Lebouvier T, Neunlist M, BruleydesVarannes $\mathrm{S}$, et al. Colonic Biopsies to Assess the Neuropathology of Parkinson's Disease and Its Relationship with Symptoms. PLoS One. 2010;5(9):e12728. Published online 2010 Sep 14. doi: 10.1371/journal.pone.0012728

3. Wakabayashi K, Takahashi H, Takeda S,et al. Lewy Bodies in the enteric nervous system in Parkinson's disease. Arch HistolCytol. 1989;52(Supplement P):191-194.

4. Braak H, de Vos RAl, Bohl J, et al. Gastric $\alpha$-synuclein immunoreactive inclusions in Meissner's and Auerbach's plexuses in cases staged for Parkinson's disease-related brain pathology. Neurosci Lett. 2006;396(1):67-72.

5. Hawkes CH, Del Tredici K, Braak H. Parkinson's disease: a dual-hit hypothesis. Neuropathol Appl Neurobiol. 2007;33(6):599-614.

6. Minguez-Castellanos A, Chamorro CE, Escamilla-Sevilla F, et al. Do $\alpha$-synuclein aggregates in autonomic plexuses predate Lewy body disorders?: a cohort study. Neurology. 2007;68(23):2012-2018. doi: 10.1212/01.wnl.0000264429. 59379.d9

7. Holmqvist S, Chutna O, Bousset L, et al. Direct evidence of Parkinson pathology spread from the gastrointestinal tract to the brain in rats. ActaNeuropathol. 2014;128(6):805-820.

8. IranzoA, FernándezArcos A, Tolosa E, etal. Neurodegenerative disorder risk in idiopathic REM sleep behavior disorder: study in 147 patients. PLoS One. 2014;9(2):e89741. doi: 10.1371/journal.pone.0089741. 
9. Gjerløff T, Fedorova T, Knudsen $\mathrm{K}$, et al. Imaging acetylcholinesterase density in peripheral organs in Parkinson's disease with 11C-donepezil PET. Brain. 2015;138(3):653-663. doi: 10.1093/brain/awu369

10. Porter AJ, Wattchow DA, Brookes $\mathrm{SJH}$, et al. Cholinergic and nitrergic interneurones in the myenteric plexus of the human colon. Gut. 2002;51(1):70-75.

11. Molloy S, McKeith IG, O'Brien JT, Burn DJ. The role of levodopa in the management of dementia with Lewy bodies. J Neurol Neurosurg Psychiatry.2005;76(9):1200-1203.

12. Lepkowsky CM. Medications Linked to Cognitive Impairment in Older Adults. Practice Innovations. 2016;1(4):253-264. doi: $10.1037 /$ pri0000033

13. Dupont Pharmaceuticals: Product Information: Sinemet $C R$ (carbidopa-levodopa), Wilmington, DE, 2016.

14. Jost WH, Schimrigk K. Constipation in Parkinson's disease. Klinische Wochenschrift. 1991;69(20):906-909.

15. Kaye J, Gage H, Kimber A, et al. Excess burden of constipation in Parkinson's disease: a pilot study. Mov Disord. 2006;21(8):1270-1273. doi:10.1002/mds.20942

16. Phillips C, Polakoff D, Maue SK, et al. Assessment of Constipation Management in Long-Term Care Patients. J Am Med Dir Assoc. 2001;2(4):149-154.

17. Kosaka K, Oyanagi S, Matsushita M, et al. Presenile dementia with Alzheimer-, Pick- and Lewy-body changes. Acta Neuropathol. 1976;36(3):221-233.

18. Perry EK, Smith CJ, Court JA, et al. Cholinergic nicotinic and muscarinic receptors in dementia of Alzheimer, Parkinson and Lewy body types. J Neural. 1990;2(3):149-158.

19. McKeith IG, Galasko D, Kosaka K, et al. Consensus guidelines for the clinical and pathologic diagnosis of dementia with Lewy bodies (DLB): report of the consortium on DLB international workshop. Neurology. 1996;47(5):1113-1124.

20. McKeith IG. Spectrum of Parkinson's disease, Parkinson's dementia, and Lewy body dementia. Neurol Clin. 2000;18(4):865-902.

21. Perez-Lloret S, Barrantes FJ. Deficits in cholinergic neurotransmission and their clinical correlates in Parkinson's disease. NPJ Parkinsons Dis. 2016;2:16001. doi:10.1038/ npjparkd.2016.1

22. Lepkowsky CM. Mechanisms of $\alpha$-synuclein pathology and treatment in the enteric nervous system. Int J Gen Sci. 2017;4(1):1-6. doi: 10.15226/2377-4274/4/1/00116

23. Bosboom JLW, Stoffers D, Wolters EC. Cognitive dysfunction and dementia in Parkinson's disease. J Neural Transm. 2004;111(10):1303-1315.

24. Birks JS. Cholinesterase inhibitors for Alzheimer's disease. Cochrane Database Syst Rev. 2006 Jan 25;(1):CD005593. doi: 10.1002/14651858.CD005593
25. Minett TSC, Thomas A, Wilkinson LM, et al. What happens when donepezil is suddenly withdrawn? An open label trial in dementia with Lewy bodies and Parkinson's disease with dementia. Int J Geriatr Psychiatry. 2003;18(11):988-993.

26. Mori E, Ikeda M, Kosaka K. Donepezil for dementia with Lewy bodies: a randomized, placebo-controlled trial. Ann Neurol. 2012;72(1):41-52.

27. Mori E, Ikeda M, Nagai R, et al. Long-term donepezil use for dementia with Lewy bodies: results from an open-label extension of Phase III trial. Alzheimers Res Ther. 2015;7(1):5. doi: 10.1186/s13195-014-0081-2

28. Rolinski M, Fox C, Maidment I, et al. Cholinesterase inhibitors for dementia with Lewy bodies, Parkinson's disease dementia and cognitive impairment in Parkinson's disease. Cochrane Database Syst Rev. 2012 Mar 14;(3):CD006504. doi: 10.1002/14651858.CD006504.pub2

29. Jacobsen FM, Comas-Díaz L. Donepezil for psychotropicinduced memory loss. J Clin Psychiatry. 1999;60(10):698-704.

30. Broad J, Kung VWS, Boundouki G, et al. Cholinergic interactions between donepezil and prucalopride in human colon: potential to treat severe intestinal dysmotility. $\mathrm{Br} \mathrm{J}$ Pharmacol. 2013;170(6):1253-1261. doi: 10.1111/bph.12397

31. Davidsson P, Blennow K, Andreasen N, Eriksson B, Minthon $L$, Hesse C. Differential increase in cerebrospinal fluid-acetylcholinesterase after treatment with acetylcholinesterase inhibitors in patients with Alzheimer's disease. Neurosci Lett. 2001;300(3):157-160. [PubMed]

32. Wilkinson DG, Francis PT, Schwam E, Payne-Parrish J. Cholinesterase inhibitors used in the treatment of Alzheimer's disease: the relationship between pharmacological effects and clinical efficacy. Drugs Aging. 2004;21(7):453-478. [PubMed]

33. Parsons CG, Danysz W, Dekundy A, Pulte I. Memantine and cholinesterase inhibitors: Complementary mechanisms in the treatment of Alzheimer's disease. Neurotox Res. 2013;24(3):358-369. doi: 10.1007/s12640-013-9398-z

34. Di Angelantonio S, Bernardi G, Mercuri NB. Donepezil modulates nicotinic receptors of substantia nigra dopaminergic neurons. Br J Pharmacol. 2004;141(4):644652. doi: $10.1038 /$ sj.bjp. 0705660

35. Zhao YJ, Wee HL, Chan Y-H, et al. Progression of Parkinson's disease as evaluated by Hoehn and Yahr stage transition times. J Mov Disord. 2010;25(6):710-716. doi: 10.1002/ mds. 22875

36. Folstein MF, Folstein SE, McHugh PR. Mini-mental state: A practical method for grading the cognitive state of patients for the clinician. J Psychiatr Res. 1975;12(3):189-198. PMID: 1202204

37. Galvin J. The Quick Dementia Rating System (QDRS): A rapid dementia staging tool. Alzheimers Dement (Amst). 2015;1(2):249-259. doi: 10.1016/j.dadm.2015.03.003 
38. Galvin J. Improving the clinical detection of Lewy body dementia with the Lewy body composite risk score. Alzheimers Dement (Amst). 2015;1(3):316-324. doi: 10.1016/j.dadm.2015.05.004

39. Lepkowsky CM. Donepezil for Lewy Body constipation: A six month follow-up. J Mol Genet Med. 2017;11(3):287.doi: 10.4172/1747-0862.1000287.

40. Lepkowsky CM. Donepezil for Constipation in Lewy body disease: A twelve month follow-up. J Mol Genet Med. 2018;12(1):337. doi: 10.4172/1747-0862.1000337

41. Lepkowsky, CM. Donepezil for $\alpha$-synuclein Constipation: An 18 Month Follow-Up. POJ Clin Case Rep. 2018;1(1):1-4. doi: 10.32648/2639-3298/1/1/003

42. Guilloux JP, Mendez-David I, Pehrson A, et al. Antidepressant and anxiolytic potential of the multimodal antidepressant vortioxetine (Lu AA21004) assessed by behavioural and neurogenesis outcomes in mice. Neuropharmacology. 2013;73:147-159. doi: 10.1016/j.neuropharm.2013.05.014

43. Alvarez E, Perez V,Dragheim M, Loft $\mathrm{H}$, Artigas F. A doubleblind, randomized, placebo-controlled, active reference study of Lu AA21004 in patients with major depressive disorder. Int J Neuropsychopharmacol. 2012;15(5):589-600. doi: $10.1017 /$ S1461145711001027

44. Boulenger JP, Loft H, Florea I. A randomized clinical study of Lu AA21004 in the prevention of relapse in patients with major depressive disorder. J Psychopharmacol. 2012;26(11):14081416. doi: $10.1177 / 0269881112441866$

45. Henigsberg $N$, Mahableshwarkar AR, Jacobsen $P$, Chen $Y$, Thase ME. A randomized, double-blind, placebo-controlled 8-week trial of the efficacy and tolerability of multiple doses of Lu AA21004 in adults with major depressive disorder. J Clin Psychiatry. 2012;73(7):953-959. doi: 10.4088/JCP.11m07470

46. Jain $\mathrm{R}$, Mahableshwarkar $\mathrm{AR}$, Jacobsen $\mathrm{PL}$, Chen $\mathrm{Y}$, Thase ME. A randomized, double-blind, placebo-controlled 6-wk trial of the efficacy and tolerability of $5 \mathrm{mg}$ vortioxetine in adults with major depressive disorder. Int J Neuropsychopharmacol. 2013;16(2):313-321. doi: 10.1017/S1461145712000727

47. Mahableshwarkar AR, Jacobsen PL, Chen Y. A randomized, double-blind trial of $2.5 \mathrm{mg}$ and $5 \mathrm{mg}$ vortioxetine (Lu AA21004) versus placebo for 8 weeks in adults with major depressive disorder. Curr Med Res Opin. 2013;29(3):217226. doi: $10.1185 / 03007995.2012 .761600$

48. Theunissen EL, Street $D, H ø j e r ~ A M$, Vermeeren $A$, van Oers $A$, Ramaekers JG. A randomized trial on the acute and steadystate effects of a new antidepressant, vortioxetine (Lu AA21004), on actual driving and cognition. Clin Pharmacol Ther. 2013;93(6):493-501. doi: 10.1038/clpt.2013.39

49. Citrome L. Vortioxetine for major depressive disorder: a systematic review of the efficacy and safety profile for this newly approved antidepressant-what is the number needed to treat, number needed to harm and likelihood to be helped or harmed? Int J Clin Pract. 2014;68(1):60-82. doi: 10.1111/ijcp.12350

50. Garnock-Jones KP. Vortioxetine: a review of its use in major depressive disorder. CNS Drugs. 2014;28(9):855-74. doi: $10.1007 / \mathrm{s} 40263-014-0195-\mathrm{x}$

51. Connolly KR, Thase ME. Vortioxetine: a New Treatment for Major Depressive Disorder. Expert Opin Pharmacother. 2015;17(3):421-431. doi: 10.1517/14656566.2016.1133588

52. Jacobsen $P$, Mahableshwarkar AR, Serenko $M$, Chen $Y$, Trivedi M. A randomized, double-blind, placebo controlled study of the efficacy and safety of vortioxetine $10 \mathrm{mg}$ and $20 \mathrm{mg}$ in adults with major depressive disorder. J Clin Psychiatry. 2015;76(5):575-82. doi: 10.4088/JCP.14m09335

53. Mahableshwarkar AR, Jacobsen $\mathrm{PL}$, Chen $\mathrm{Y}$, Serenko $\mathrm{M}$, Trivedi MH. A randomized, double-blind, duloxetinereferenced study comparing efficacy and tolerability of 2 fixed doses of vortioxetine in the acute treatment of adults with MDD. Psychopharmacology. 2015;232(12):2061-2070. doi:10.1007/s00213-014-3839-0

54. Mahableshwarkar, AR, Jacobsen, PL, Serenko, M. A randomized, double-blind, placebo-controlled study of the efficacy and safety of 2 doses of vortioxetine in adults with major depressive disorder. J Clin Psychiatry. 2015;76(5):583591. doi: 10.4088/JCP.14m09337

55. Thase ME, Mahableshwarkar A, Dragheim M, Loft H, Vieta E. A meta-analysis of randomized, placebo-controlled trials of vortioxetine for the treatment of major depressive disorder in adults. Eur. Neuropsychopharmacol. 2016;26(6):979-993. doi: 10.1016/j.euroneuro.2016.03.007

56. Mahableshwarkar, AR, Jacobsen, PL, Serenko, M. A randomized, double-blind, fixed-dose study comparing the efficacy and tolerability of vortioxetine 2.5 and $10 \mathrm{mg}$ in acute treatment of adults with generalized anxiety disorder. Hum Psychopharmacol. 2014a;29(1):64-72. doi: 10.1002/ hup. 2371

57. Mahableshwarkar, AR, Jacobsen, $\mathrm{PL}$, Chen $\mathrm{Y}$, Simon JS. A randomised, double-blind, placebo-controlled, duloxetine-referenced study of the efficacy and tolerability of vortioxetine in the acute treatment of adults with generalised anxiety disorder. Int J Clin Pract. 2014b;68(1): 49-59. doi: 10.1111/ijcp.12328

58. Jensen JB, du Jardin $K G$, Song $D$, et al. Vortioxetine, but not escitalopram or duloxetine, reverses memory impairment induced by central 5-HT depletion in rats: evidence for direct 5-HT receptor modulation. Eur Neuropsychopharmacol. 2014;24(1):148-159. doi: 10.1016/j.euroneuro.2013.10.011

59. McIntyre R.S., Lophaven, S., Olsen K. A randomized, doubleblind, placebo-controlled study of vortioxetine on cognitive function in depressed adults. Int J Neuropsychopharm. 2014;17(10):1557-1567. doi: 10.1017/\$1461145714000546

60. Mahableshwarkar A, Zajecka J, Jacobson W, Chen Y, Keefe RS. A Randomized, Placebo-Controlled, Active-Reference, Double-Blind, Flexible-Dose Study of the Efficacy of

Citation: Charles M. Lepkowsky (2021). Donepezil and a-synuclein Constipation: A 48 Month Follow-Up. POJ Clin Case Rep. 3(1):1-7. 
Vortioxetine on Cognitive Function in Major Depressive Disorder. Neuropsychopharmacology. 2015;40(8):20252037. doi: $10.1038 / n p p .2015 .52$

61. Vieta W, Sluth LB, Olsen CK. The effects of vortioxetine on cognitive dysfunction in patients with inadequate response to current antidepressants in major depressive disorder: A short-term, randomized, double-blind, exploratory study versus escitalopram. J Affect Disord. 2018;227:803-809. doi: 10.1016/j.jad.2017.11.053

62. Al-Sukhni M, Maruschak NA, Mclntyre RS. Vortioxetine: a review of efficacy, safety and tolerability with a focus on cognitive symptoms in major depressive disorder. Expert Opin Drug Saf. 2015;14(8):1291-1304. doi: $10.1517 / 14740338.2015 .1046836$

63. Lundbeck A/S. FDA updates Trintellix ${ }^{\circledR}$ (vortioxetine) label to include data showing improvement in processing speed, an important aspect of cognitive function in acute Major Depressive Disorder (MDD). 2018. Available from: http:// investor.lundbeck.com/news-releases/news-releasedetails/fda-updates-trintellixr-vortioxetine-label-includedata-showing. Accessed 09/18/2018.

64. Lepkowsky, CM. Vortioxetine and Lewy Body Disorders. International Research Journal of Pharmacy and Medical Sciences. 2019;2(2):2-20. doi: 10.5281/zenodo. 2562413

65. Lepkowsky, CM. Donepezil and $\alpha$-synuclein Constipation: A 36 Month Follow-Up. POJ Clin Case Rep. 2019;2(1):1-7. doi: 10.32648/2639-3298/2/1/002
66. Chen G, Højer AM, Areberg J, Nomikos G. Vortioxetine: Clinical Pharmacokinetics and Drug Interactions. ClinPharmacokinet. 2018;57(6):673-686. doi: 10.1007/ s40262-017-0612-7

67. Sanchez C, Asin KE, Artigas F. Vortioxetine, a novel antidepressant with multimodal activity: Review of preclinical and clinical data. PharmacolTher. 2015;145:4357. doi: 10.1016/j.pharmthera.2014.07.001

68. Spina E, Santoro V. Drug interactions with vortioxetine, a new multimodal antidepressant. Riv Psichiatr. 2015;50(5):210-5. doi: $10.1708 / 2040.22160$.

69. Drugbank. Vortioxetine: Interactions. 2018. Available from: https://www.drugbank.ca/drugs/DB09068. Accessed: 09/26/2018.

70. U.S. Government. Drug-Drug Interactions. Available from: http://m.usgovxml.com/DrugInt.aspx?dn=SINEMET. Accessed: 09/26/2018.

71. Ladefoged LK, Munro L, Pedersen AJ, et al. Modeling and mutational analysis of the binding mode for the multimodal antidepressant drug vortioxetine to the human 5-HT3A receptor. Mol Pharmacol. 2018;94(6):1421-1434. doi: 10.1124/mol.118.113530 